\title{
Consistent Failure to Produce a Cognitive Load Effect in Visual Working Memory Using a Standard Dual-Task Procedure
}

\author{
Timothy J. Ricker ${ }^{1}$ and Evie Vergauwe ${ }^{2}$ \\ ${ }^{1}$ College of Staten Island, City University of New York, US \\ 2 University of Geneva, $\mathrm{CH}$ \\ Corresponding author: Timothy J. Ricker (Timothy.Ricker@csi.cuny.edu)
}

\begin{abstract}
Working memory performance is impaired when an attention-demanding task is executed during memory retention. The cognitive load effect is the consistent finding that the size of the memory impairment is determined by the relative amount of time that the secondary processing task occupies attention during memory retention. Cognitive load has been proposed to be a Priority-A benchmark any model of working memory should be able to explain (Oberauer et al., 2018), in part because the effect appears to generalize across different experimental procedures and materials. Using a standard dual-task procedure, we detail four experiments using a visual working memory recall task, two requiring memory for low-level features and two requiring memory for canonical angles (up, down, left, right, etc.). In all four experiments, we failed to find a cognitive load effect, calling into question the generality of the cognitive load effect and whether it is driving forgetting in multitasking contexts.
\end{abstract}

Keywords: working memory; short-term memory; visual memory; multitasking; cognitive load; forgetting

The working memory system maintains information in an immediately available state for ongoing cognition. Much recent work has argued that concurrent processing demands of a task, or cognitive load, drive forgetting from working memory (Barrouillet, Bernardin, \& Camos, 2004; Barrouillet, Bernardin, Portrat, Vergauwe, \& Camos, 2007; Barrouillet \& Camos, 2015; Barrouillet, Portrat, \& Camos, 2011; Bayliss, Bogdanovs, \& Jarrold, 2015; Camos, Lagner, \& Barrouillet, 2009; Hudjetz \& Oberauer, 2007; Liefooghe, Barrouillet, Vandierendonck, \& Camos, 2008; Vergauwe, Barrouillet, \& Camos, 2010). Cognitive load is a measure of attentional demand that indexes how much maintenance can occur during memory retention. Attention is thought to maintain memory representations in the absence of verbal rehearsal through a process called refreshing (Barrouillet et al., 2004; Camos et al., 2018; Cowan, 1992; Raye, Johnson, Mitchell, Greene, \& Johnson, 2007; Vergauwe \& Cowan, 2014). When attention is needed for a concurrent task, it is not available for refreshing and, as a result, forgetting occurs.

\section{An important role for cognitive load in working memory}

Cognitive load is often defined as the proportion of time attention is occupied by a secondary task during memory retention, which can be increased by, for example, increasing the pace at which a secondary task needs to be performed (Barrouillet et al., 2004; Barrouillet et al., 2007; Barrouillet \& Camos, 2015; Barrouillet et al., 2011; Hudjetz \& Oberauer, 2007). This conception follows from the assumptions of the Time-Based Resource-Sharing (TBRS) model proposed by Barrouillet et al. (2004) who assumed that unattended working memory representations are forgotten with the passage of time. In order to keep memories from becoming inactive and forgotten, attention must be directed toward each representation, in sequence (i.e., refreshing). Critically, the TBRS model assumes that any secondary task that requires attention will prevent refreshing from occurring at the same time. Higher cognitive loads mean less time 
is available for memory maintenance and more time for trace decay to occur. Thus, the cognitive load of the secondary task has an inverse relationship to the total number of items that can be maintained in working memory. There are several alternative models of cognitive load effects with somewhat different assumptions, but all of them predict a strong, inverse relationship between cognitive load and the total number of items remembered in dual-task situations (Lemaire \& Portrat, 2018; Oberauer \& Lewandowsky, 2011; Oberauer, Lewandowsky, Farrell, Jarrold, \& Greaves, 2012; Portrat \& Lemaire, 2015). Accordingly, the cognitive load effect has been proposed to be a Priority-A benchmark any model of working memory should be able to explain (Oberauer et al., 2018), in part because the effect appears to generalize across different experimental procedures and materials.

The notion that forgetting is always entirely determined by cognitive load was, however, questioned by Ricker and Cowan (2010) and Vergauwe, Camos, and Barrouillet (2014) who raised the possibility that memory representations of detailed sensory features cannot be maintained by attention-based mechanisms and, therefore, are forgotten gradually across the absolute length of a retention interval. This previous work suggests that a pre-existing conceptual representation may be necessary for attention-based refreshing to function. Critically, under this assumption, one must predict that memory materials predominantly composed of low-level perceptual features do not show cognitive load effects. In the experiments that follow, we tested the prediction that memory items predominantly composed of low-level perceptual features will not show a cognitive load effect, whereas memory items predominantly composed of conceptual representations will show a cognitive load effect.

\section{Experiment 1}

In our first experiment we test the prediction that materials predominantly composed of low-level sensory features lacking a conceptual long-term memory representation do not produce cognitive load effects. If attention cannot be used to maintain such representations, then memory performance for these stimuli should not suffer from increased cognitive load of the secondary task.

\section{Method}

\section{Participants}

One-hundred and six students (67 female, ages $18-41)^{1}$ from universities in the United States participated in the experiment in exchange for partial course credit. Ten participants were excluded from the analysis because they did not complete the experiment.

In cognitive load experiments, the failure to observe a cognitive load effect could be due to the secondary task not inducing a load or because participants fail to perform the secondary task. In order to ensure that the secondary task was performed diligently, we only include trials with perfect secondary task accuracy in our analysis. This resulted in five participants without any data for analysis in one or more experimental conditions who were removed from the analyses reported in the results section (see Table $\mathbf{1}$ for results with alternative filtering). The inferential results reported in the text are reported in column 3 of Table $\mathbf{1}$ (in bold font) for all experiments. This left forty-three participants included in the analysis of Experiment 1a and forty-eight participants included in the analysis of Experiment $1 \mathrm{~b}$.

\section{Materials}

The memory items were rings with a dot placed randomly along the outer circumference (Figure 1). The location of the dot on the edge of the circle was determined randomly on each trial, ranging anywhere within 90 degrees to the left or right of the top of the circle (Experiment 1a) or across the entire range of the circle (Experiment 1b). Each stimulus had the following properties in Experiments 1a \& 1b respectively: ring diameter $2.5 / 2.3 \mathrm{~cm}$, dot diameter $0.4 / 0.3 \mathrm{~cm}$, ring center located at one of eight locations $4.5 / 4.2 \mathrm{~cm}$ from the center of the screen. The 8 locations were the location directly above the center of the screen and the 7 remaining locations that resulted from 45 degrees steps around a circle.

The response probe consisted of presentation of the memory stimulus ring in its original color, size, and location but with the dot located in the center of the ring. Participants were instructed to move the dot to the location in which they saw it during study.

\footnotetext{
${ }^{1}$ Six of the participants in Experiment 1a did not complete the experiment and the program failed to record their demographic data as a result. The gender and age breakdowns omit these participants. Only participants that completed the full experiment are included in the data analysis.
} 
Table 1: Performance Metrics across Experiments and Inclusion Criteria.

\begin{tabular}{|c|c|c|c|c|}
\hline Participant Inclusion Criteria & $\begin{array}{l}.8 \text { secondary task } \\
\text { accuracy or better }\end{array}$ & $\begin{array}{l}.8 \text { secondary } \\
\text { task accuracy } \\
\text { or better }\end{array}$ & $\begin{array}{c}\text { Must have a } \\
\text { high accuracy* } \\
\text { trial in all } \\
\text { conditions }\end{array}$ & $\begin{array}{l}\text { All participants } \\
\text { that completed } \\
\text { the study }\end{array}$ \\
\hline Trial Inclusion Criteria & $\begin{array}{l}\text { High accuracy* } \\
\text { trials only }\end{array}$ & All trials & $\begin{array}{l}\text { High accuracy* } \\
\text { trials only }\end{array}$ & All trials \\
\hline \multicolumn{5}{|c|}{ Experiment 1a (continuous memoranda + tone task) } \\
\hline Participant N & 38 & 38 & 43 & 44 \\
\hline Effect Size $(d)$ & 0.11 & 0.42 & 0.07 & 0.46 \\
\hline Bayes Factor $\left(\mathrm{H}_{10}\right)$ & 0.33 & 0.80 & 0.12 & 3.94 \\
\hline \multicolumn{5}{|c|}{ Experiment 1b (continuous memoranda + parity task) } \\
\hline Participant N & 30 & 30 & 48 & 52 \\
\hline Effect Size $(d)$ & 0.13 & 0.50 & 0.12 & 0.43 \\
\hline Bayes Factor $\left(\mathrm{H}_{10}\right)$ & 0.12 & 1.05 & 0.08 & 3.89 \\
\hline \multicolumn{5}{|c|}{ Experiment 2a (canonical memoranda + tone task) } \\
\hline Participant N & 14 & 14 & 22 & 30 \\
\hline Effect Size $(d)$ & -0.34 & 0.19 & 0.01 & 0.28 \\
\hline Bayes Factor $\left(\mathrm{H}_{10}\right)$ & 0.31 & 0.14 & 0.07 & 0.19 \\
\hline \multicolumn{5}{|c|}{ Experiment $2 \mathrm{~b}$ (canonical memoranda + parity task) } \\
\hline Participant N & 24 & 24 & 37 & 53 \\
\hline Effect Size (d) & 0.24 & 0.48 & 0.24 & 0.47 \\
\hline Bayes Factor $\left(\mathrm{H}_{10}\right)$ & 0.24 & 0.70 & 0.29 & 14.82 \\
\hline
\end{tabular}

Note: Effect sizes and Bayes factors pertain to the effect of Cognitive Load.

*A high accuracy trial is one with perfect performance on the secondary task.

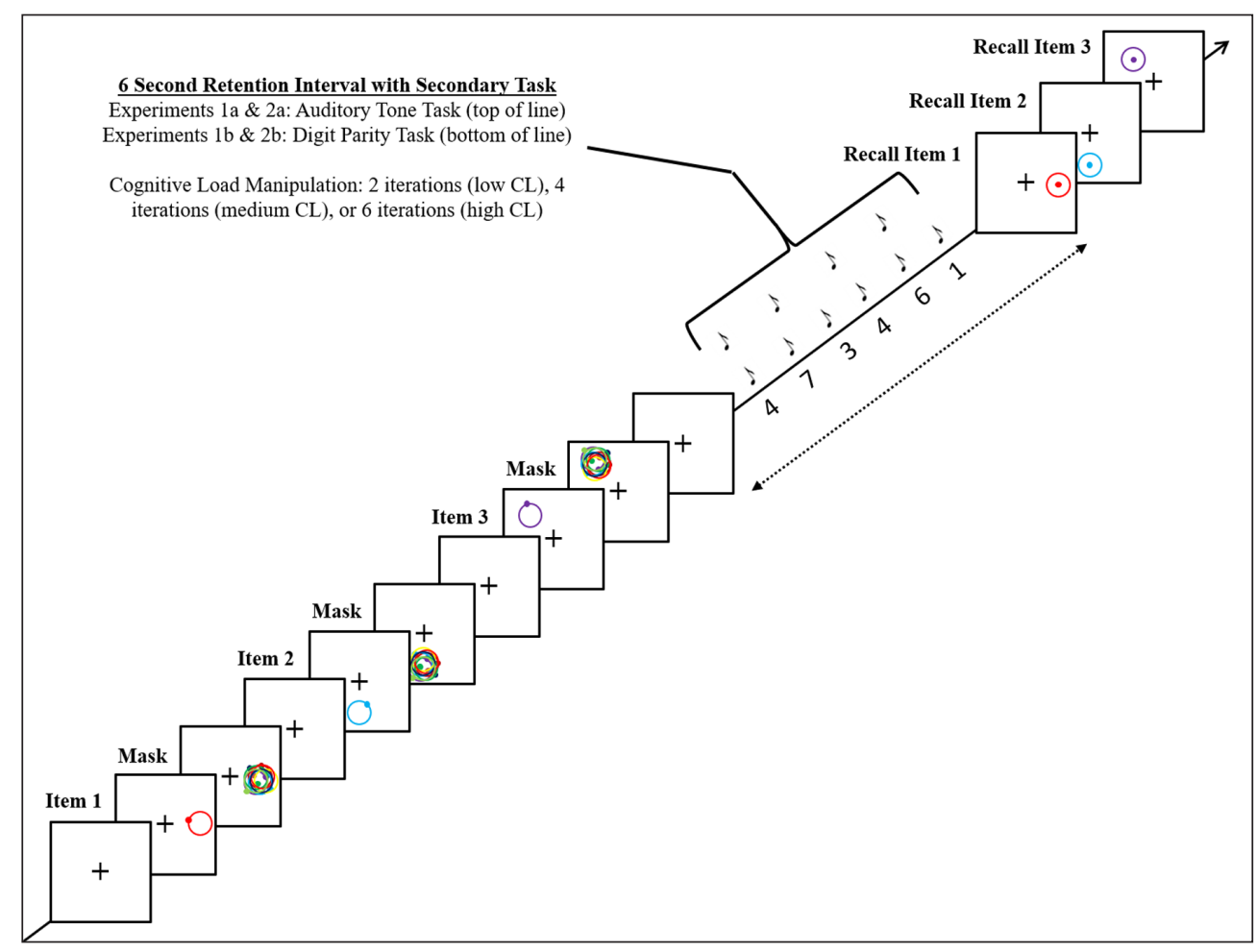

Figure 1: An example of a single experimental trial in Experiment 1. 
In Experiment 1a participants heard a series of tones during our secondary task. Each individual tone was presented for $250 \mathrm{~ms}$ at a high $(523.252 \mathrm{~Hz})$ or low $(130.813 \mathrm{~Hz})$ pitch. In Experiment 1b participants saw a series of numbers during the secondary task. The numbers ranged from 1 to 8 and were presented visually at the center of the screen in 30-point font. Each number was presented until a response was made or until the next stimulus was presented. Two different secondary tasks were used to assess the robustness of our findings. See the design section for the presentation schedule in each cognitive load condition.

\section{Design}

We used a within-subjects design in which all non-fixed variables, such as item location, the angle of the dot location, and the cognitive load, were determined randomly with an equal probability on each trial. There were 3 possible levels of cognitive load, our variable of interest, resulting in a one-factor design with 3 levels. In Experiment 1a, one two-choice tone judgement was to be performed every 3 seconds, every 1.5 seconds, or every second, for the low, medium, and high load conditions respectively. The retention interval was always 6 s. Experiment $1 \mathrm{~b}$ used an identical design, except that the two-alternative choice task was a parity judgement of a presented number instead of a tone judgment task. There were 8 practice trials in Experiment $1 \mathrm{a}$ and 12 practice trials in Experiment 1b, followed by either 4 or 5 blocks of 30 experimental trials in both experiments.

\section{Procedure}

Except for the nature of the secondary task, all aspects of the procedure were identical between Experiments $1 \mathrm{a}$ and $1 \mathrm{~b}$, see Figure $\mathbf{1}$ for a single experimental trial. Participants pressed the space bar to begin each trial, which began with a white fixation cross presented at the center of a black screen for 500 ms. Next came item presentation, with each item being presented one at a time and followed by a post-perceptual mask and a consolidation period before presentation of the next item or, in the case of the final item, before the retention interval began. Each item was displayed for $400 \mathrm{~ms}$, followed by a postperceptual mask displayed for $200 \mathrm{~ms}$. The mask was presented at the same location as the memory item and consisted of 8 circles, each slightly displaced from the location of item presentation and eight dots randomly placed in the region of item presentation. Next, there was a 200 ms blank screen during which only the fixation cross was presented.

After all three memory items were presented the 6 s retention interval began. The first stimulus in the secondary cognitive-load task was presented at the time of retention interval onset. In Experiment 1a participants heard a series of tones and it was the participant's task to push the down arrow key if the tone was low pitched or the up-arrow key if the tone was high pitched. In Experiment 1b participants saw a series of numbers presented in the center of the screen. It was the participant's task to push the 'a' key if the number was odd or the 's' key if the number was even. The level of cognitive load for the current trial determined the rate and number of secondary-task stimulus.

After the retention interval, memory for each of the three items was tested in the order of item presentation. For each item, a probe ring was presented in the location of the original memory item with a dot in its center. Participants were to move the dot to the original location of the memory item. Feedback was given for all three memory items simultaneously by displaying the correct location of each dot and the participant's entered response. Sound feedback was also given during this period. In Experiment 1a, if the average error on the present trial was less than 12 degrees, an increasing-frequency happy sound sequence was played. If average error was between 12 and 40 degrees a slightly increasing frequency neutral sound sequence was played. If the average error was greater than 40 degrees, a decreasing frequency sad sound sequence was played. In Experiment 1b, the feedback tone thresholds were shifted to 20 and 60 degrees respectively to account for the larger stimulus presentation space when using the entire circle.

\section{Results}

Visual examination of Figure 2 shows no effect of Cognitive Load on mean response error in Experiment 1a or 1b. Mean error was overall larger in Experiment 1b than in 1a, which was to be expected given that the stimulus space was larger in Experiment $1 \mathrm{~b}$ (see the materials section for stimulus details). RepeatedMeasures ANOVAs of mean response error as a function of Cognitive Load confirms the lack of a cognitive load effect in Experiment 1a, $F(2,84)=1.16, \mathrm{~d}_{\mathrm{z}}=0.07$, Bayes factor $=8.62$ in favor of the null (means: 0.33 $=25,0.67=24,1.00=25)$, and in Experiment $1 \mathrm{~b}, F(2,94)=0.82, \mathrm{~d}_{\mathrm{z}}=0.12$, Bayes factor $=12.83$ in favor of the null (means: $0.33=50,0.67=50,1.00=52$ ). The Bayes factors were calculated following the method described by (Rouder, Morey, Speckman, \& Province, 2012) using the BayesFactor package for R (Morey \& Rouder, 2015) with the standard deviation of the effect size set to $(\sqrt{ } 2) / 2$. 

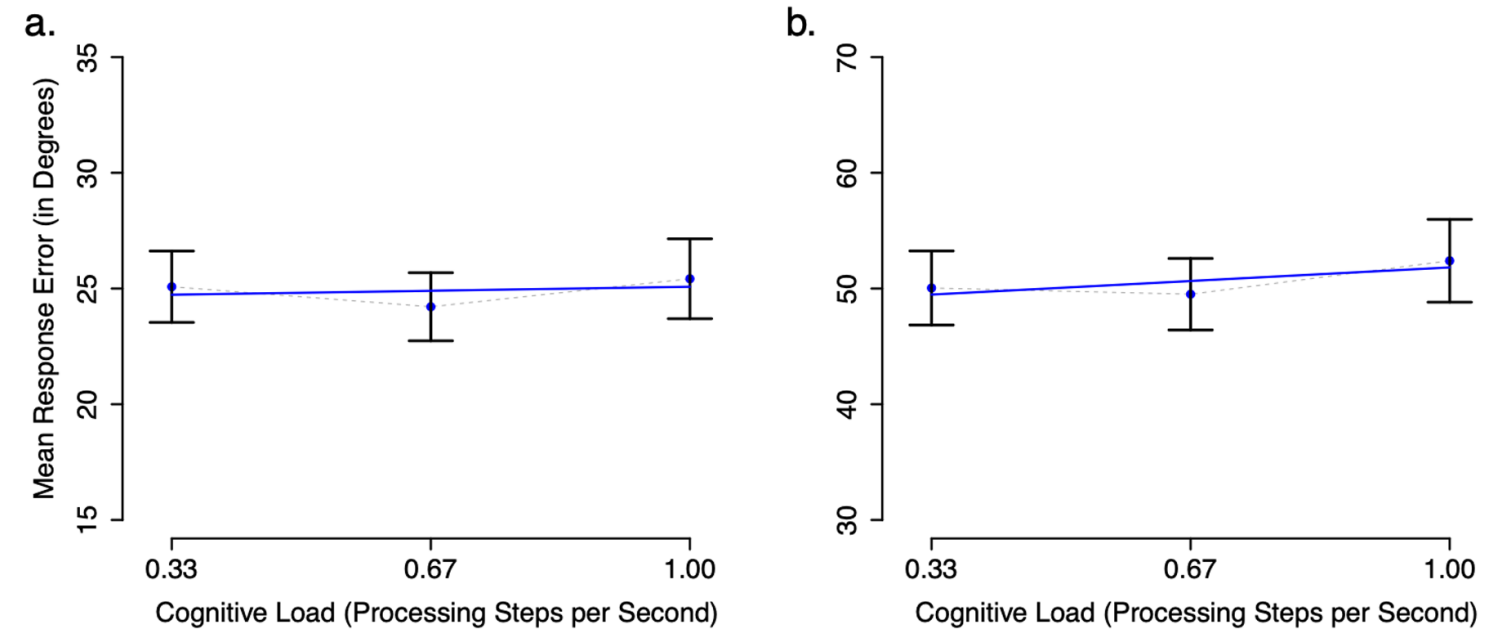

Figure 2: Mean response error in degrees of angle by cognitive load condition (number of digits/6s retention interval) observed in Experiment 1a (continuous memoranda + tone task; panel a) and Experiment 1b (continuous memoranda + parity task; panel b) Error bars represent standard error of the mean. The blue line shows the linear regression of mean response error on cognitive load. Note that the $y$-axis is compressed in panel a. relative to panel b. due to Experiment 1a having one half the total stimulus range compared to Experiment 1b.

\section{Discussion}

Experiments $1 \mathrm{a}$ and $1 \mathrm{~b}$ give clear evidence against an effect of cognitive load on memory performance when remembering materials that are predominantly composed of continuous low-level perceptual features. As can be seen in Table 1, using other types of data filtering to assess the robustness of our findings show that some modest evidence for an effect of cognitive load can be found, but only when no filtering was applied to the data, which has, to our knowledge, never been done. Cognitive load studies typically exclude participants and/or trials with poor secondary-task performance. Note that we have used cognitive load manipulations that correspond to three different pace levels that have frequently been used in previous cognitive load studies (e.g., Barrouillet et al., 2007; Vergauwe et al., 2010; Vergauwe, Hartstra, Barrouillet, \& Brass, 2015).

\section{Experiment 2}

In Experiment 2 we explore the same set of cognitive load conditions as in Experiment 1, but with canonical memory stimuli instead of the continuous memory stimuli. Experiments $2 \mathrm{a}$ and $2 \mathrm{~b}$ are the same as Experiments $1 \mathrm{a}$ and $1 \mathrm{~b}$, except that the location of the dots on the rings could now only appear at the four cardinal directions, up, down, left, right, and the 4 locations that lie halfway between these locations (see Figure 3 for an example). In Experiment $2 \mathrm{~b}$ we also marked the possible presentation locations of the categorical items of the probe during memory recall. We expected to find a cognitive load effect for these memoranda, given that all past research indicates that this should be the case with categorical memoranda (Barrouillet et al., 2004; Barrouillet et al., 2007; Barrouillet \& Camos, 2015; Barrouillet et al., 2011; Bayliss et al., 2015; Camos et al., 2009; Hudjetz \& Oberauer, 2007; Liefooghe et al., 2008; Vergauwe et al., 2010).

\section{Method}

\section{Participants}

Ninety students (53 female, ages 18-43) from the College of Staten Island participated in exchange for partial course credit. Seven participants were excluded from the analysis because they did not complete the experiment. After filtering out trials that did not show perfect secondary task performance, twenty-four participants did not have any data in one or more experimental conditions, leading to their exclusion from the sample. This left twenty-two participants included in the analysis of Experiment $2 \mathrm{a}$ and thirty-seven participants included in the analysis of Experiment 2b.

\section{Materials}

All materials were the same as in Experiment 1b, with the following exceptions. In Experiment 2 all memory stimuli were canonical locations on the ring, with the dot located at the top of the ring or one of the 7 other locations resulting from moving 45 degrees around the edge of the ring (see Figure 3). In Experiment 2b 


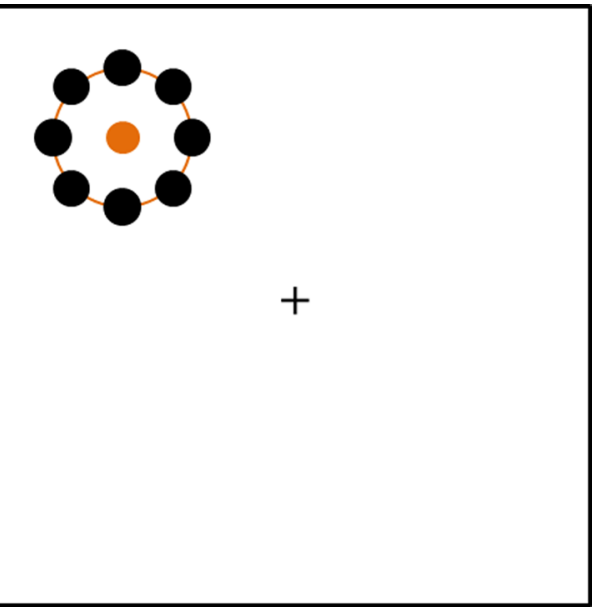

Figure 3: An example of a response probe in Experiment 2b. The black dots show the eight possible dot locations for canonical memory items. Each memory item only contained a single dot.

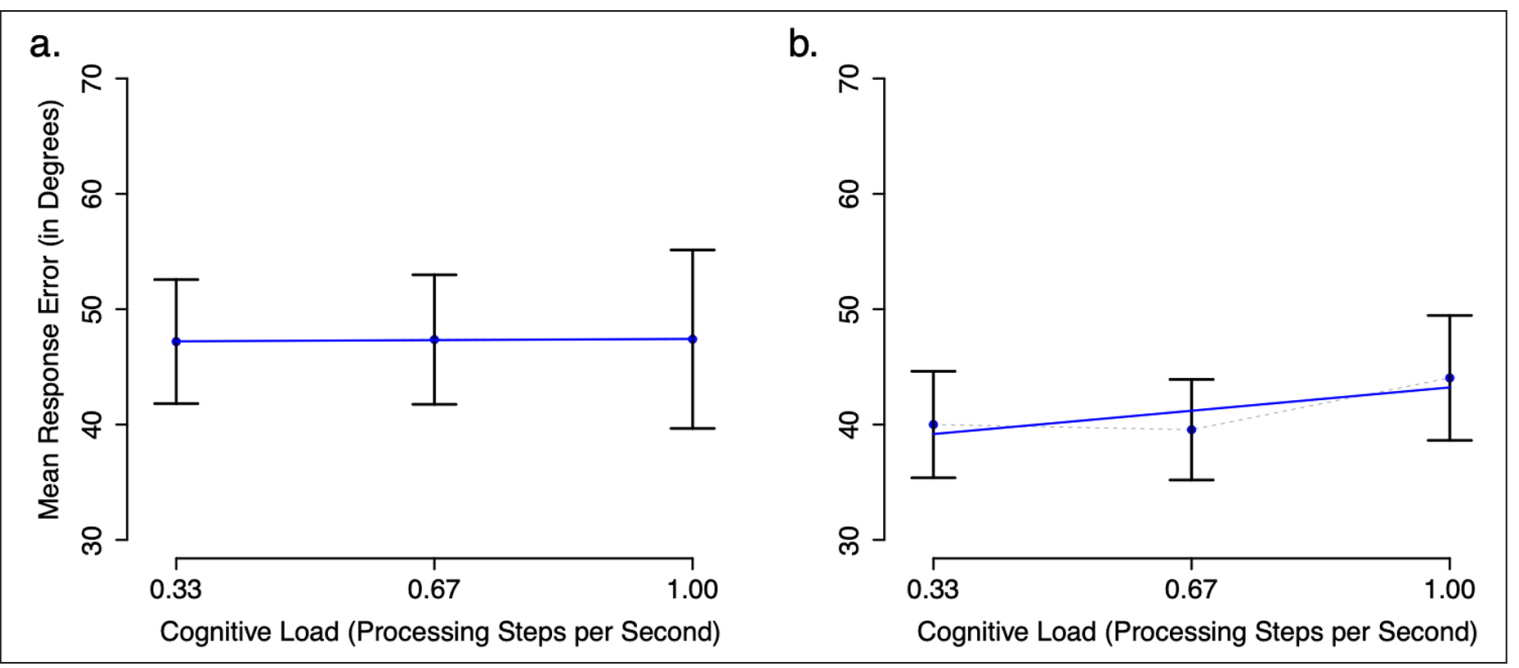

Figure 4: Mean response error in degrees of angle by cognitive load condition (number of digits/6s retention interval) observed in Experiment 2a (canonical memoranda + tone task; panel a) and experiment 2b (canonical memoranda + parity task; panel b) Error bars represent standard error of the mean. The blue lines show the linear regression of mean response error on cognitive load.

the memory-probe ring also marked all possible presentation locations with a white circle at each of the 8 locations. The secondary task stimuli in Experiments 2a and 2b were the same as those in Experiments 1a and $1 \mathrm{~b}$, respectively.

\section{Design}

All aspects of the design were the same as in Experiment 1, except that Experiments 2a and 2b had 4 blocks of 30 experimental trials.

\section{Procedure}

Except for the canonical nature of the memory stimuli in Experiment 2, all aspects of the procedure were the same in Experiment 2 as in Experiment 1. In Experiment $2 \mathrm{~b}$ the canonical nature of the stimuli was repeatedly stressed in the instructions and practice sections of the experiment. Response markers were also placed on the response probe to mark the possible stimulus locations in Experiment 2b.

\section{Results}

Visual examination of Figure 4a shows no effect of Cognitive Load on mean response error in Experiment $2 \mathrm{a}$ and the slightest hint of an effect in Experiment 2b. Repeated-Measures ANOVA of mean response error as a function of Cognitive Load confirms this lack of an effect for Experiment 2a, $F(2,42)=0.001, \mathrm{~d}_{\mathrm{z}}=0.01$, Bayes factor $=13.68$ in favor of the null (means: $0.33=47,0.67=47,1.00=47$ ), and indicate no effect in 
Experiment $2 \mathrm{~b}, F(2,72)=2.12, \mathrm{~d}_{\mathrm{z}}=0.24$, Bayes factor $=3.42$ in favor of the null (means: $0.33=40,0.67=$ $40,1.00=44)$.

\section{Discussion}

The results of Experiment 2 demonstrate no effect of cognitive load on the recall of canonical visual memory items. As can be seen in Table 1, when no filtering whatsoever was applied to the data, there was still evidence against an effect of Cognitive load in Experiment 2a, whereas there was evidence for an effect of Cognitive load in Experiment 2b.

\section{General Discussion}

We hypothesized that low-level features cannot be maintained using directed attention, whereas conceptual representations can. Therefore, we predicted no cognitive load effect for low-level features used in Experiment 1, whereas we did expect a cognitive load effect for conceptual memory materials used in Experiment 2. Despite the contrast in memory materials between the two experiments, the results were highly similar; neither experiment produced an effect of cognitive load. This is a novel finding. More research will be needed to explore why we have failed to find an effect of cognitive load in our two experiments despite consistent findings in favor of similar cognitive load effects for visuo-spatial memoranda in the published literature (e.g., Barrouillet, De Paepe, \& Langerock, 2012; Langerock, Vergauwe, \& Barrouillet, 2014; Vergauwe, Barrouillet, \& Camos, 2009; Vergauwe et al., 2010; Vergauwe, Dewaele, Langerock, \& Barrouillet, 2012; Vergauwe et al., 2015). Below, we speculate on four potential reasons.

First, one clear difference between our experiments and most of the previous work examining cognitive load effects is our use of a Brown-Peterson task. In the Brown-Peterson task all of the memory items are presented before a single retention interval, during which a series of secondary task executions is required (Brown, 1958; Jarrold, Tam, Baddeley, \& Harvey, 2011; Lucidi et al., 2016; Neath, VanWormer, Bireta, \& Surprenant, 2014; Peterson \& Peterson, 1959). Past work on cognitive load effects is largely, though not uniquely, built on the complex-span task (Barrouillet et al., 2004; Barrouillet et al., 2007; Oberauer et al., 2012; Vergauwe et al., 2009, 2010). In this latter task there is a retention interval after each memory item, with a series of secondary task executions during each retention interval. From existing theoretical perspectives there is no reason that cognitive load effects should require multiple individual retention intervals after each item, but perhaps something about multiple retention intervals contributes to cognitive load effects.

Second, the presentation duration may have played a role in our failure to observe a cognitive load effect by allowing considerable time for working memory consolidation. Working memory consolidation is the process by which a fragile sensory memory trace is stabilized into working memory and made resistant to forgetting (Chun \& Potter, 1995; Jolicœur \& Dell'Acqua, 1998; Ricker, 2015; Ricker \& Cowan, 2014). De Schrijver and Barrouillet (2017) systematically varied a period of free time between item presentation and secondary task onset during which attention could be used to focus on the memory item for consolidation. When this consolidation period was longer, they observed smaller cognitive load effects on memory performance. Perhaps the present failure to observe a cognitive load effect stems from allowing relatively long consolidation times for our memory items.

Third, the finding could be specific to the stimuli used in our study. To our knowledge, the present study is the first to use an angle reproduction task to explore cognitive load effects. Fourth, perhaps some combination of these previous explanations is responsible for our failure to observe cognitive load effects.

To conclude, the current findings are surprising and in contradiction with a large amount of past research showing the ubiquitous nature of cognitive load effects (Barrouillet et al., 2004; Barrouillet et al., 2007; Barrouillet et al., 2011; Bayliss et al., 2015; Hudjetz \& Oberauer, 2007; Oberauer et al., 2018; Vergauwe et al., $2009,2010)$. While more research is needed to understand the key factor in determining the presence vs. absence of cognitive load effects, our results show that there are clear unexpected boundary conditions to the effect.

\section{Data Accessibility Statement}

All data reported in this work are available on the Open Science Framework at https://osf.io/w9mv6/.

\section{Ethics and Consent}

The reported work was performed in accordance with the Declaration of Helsinki. Experiment 1a was approve by the University of Missouri Institutional Review Board, study \#1168779. Experiments 1b, 2a, and $2 \mathrm{~b}$ were approved by the City University of New York - University Integrated Institutional Review Board, study \#2015-1156. All participants gave informed consent prior to participation in the study. 


\section{Acknowledgements}

Thanks to Aileen Sammartano, Johna Palladino, and Cinthya Ramirez for their help with data collection.

\section{Funding Information}

This work was completed, in part, with support from Swiss National Science Foundation Grants PZ00P1154911 and PCEFP1_181141 to Evie Vergauwe.

\section{Competing Interests}

The authors have no competing interests to declare.

\section{Author Contributions}

Both authors jointly contributed to the conceptualization, design, interpretation, and write up of the reported studies. The data was collected in T.R.'s laboratory and analyzed by T.R.

\section{References}

Barrouillet, P., Bernardin, S., \& Camos, V. (2004). Time constraints and resource sharing in adults' working memory spans. Journal of Experimental Psychology: General, 133(1), 83-100. DOI: https://doi. org/10.1037/0096-3445.133.1.83

Barrouillet, P., Bernardin, S., Portrat, S., Vergauwe, E., \& Camos, V. (2007). Time and cognitive load in working memory. Journal of Experimental Psychology: Learning, Memory, and Cognition, 33(3), 570-585. DOI: https://doi.org/10.1037/0278-7393.33.3.570

Barrouillet, P., \& Camos, V. (2015). Working Memory: Loss and Reconstruction. New York, NY, US: Psychology Press. DOI: https://doi.org/10.4324/9781315755854

Barrouillet, P., De Paepe, A., \& Langerock, N. (2012). Time causes forgetting from working memory. Psychonomic bulletin \& review, 19(1), 87-92. DOI: https://doi.org/10.3758/s13423-011-0192-8

Barrouillet, P., Portrat, S., \& Camos, V. (2011). On the law relating processing to storage in working memory. Psychological review, 118(2), 175-192. DOI: https://doi.org/10.1037/a0022324

Bayliss, D. M., Bogdanovs, J., \& Jarrold, C. (2015). Consolidating working memory: Distinguishing the effects of consolidation, rehearsal and attentional refreshing in a working memory span task. Journal of Memory and Language, 81, 34-50. DOI: https://doi.org/10.1016/j.jml.2014.12.004

Brown, J. (1958). Some tests of the decay theory of immediate memory. Quarterly journal of experimental psychology, 1O(1), 12-21. DOI: https://doi.org/10.1080/17470215808416249

Camos, V., Johnson, M., Loaiza, V., Portrat, S., Souza, A., \& Vergauwe, E. (2018). What is attentional refreshing in working memory? Annals of the New York Academy of Sciences, 1424(1), 19-32. DOI: https://doi.org/10.1111/nyas.13616

Camos, V., Lagner, P., \& Barrouillet, P. (2009). Two maintenance mechanisms of verbal information in working memory. Journal of Memory and Language, 61(3), 457-469. DOI: https://doi.org/10.1016/j. jml.2009.06.002

Chun, M. M., \& Potter, M. C. (1995). A two-stage model for multiple target detection in rapid serial visual presentation. Journal of Experimental Psychology: Human Perception and Performance, 21(1), 109-127. DOI: https://doi.org/10.1037/0096-1523.21.1.109

Cowan, N. (1992). Verbal memory span and the timing of spoken recall. Journal of Memory and Language, 31(5), 668-684. DOI: https://doi.org/10.1016/0749-596X(92)90034-U

De Schrijver, S., \& Barrouillet, P. (2017). Consolidation and restoration of memory traces in working memory. Psychonomic bulletin \& review, 24(5), 1651-1657. DOI: https://doi.org/10.3758/s13423-017-1226-7

Hudjetz, A., \& Oberauer, K. (2007). The effects of processing time and processing rate on forgetting in working memory: Testing four models of the complex span paradigm. Memory \& Cognition, 35(7), 1675-1684. DOI: https://doi.org/10.3758/BF03193501

Jarrold, C., Tam, H., Baddeley, A. D., \& Harvey, C. E. (2011). How does processing affect storage in working memory tasks? Evidence for both domain-general and domain-specific effects. Journal of Experimental Psychology: Learning, Memory, and Cognition, 37(3), 688-705. DOI: https://doi.org/10.1037/a0022527

Jolicœur, P., \& Dell'Acqua, R. (1998). The demonstration of short-term consolidation. Cognitive psychology, 36(2), 138-202. DOI: https://doi.org/10.1006/cogp.1998.0684

Langerock, N., Vergauwe, E., \& Barrouillet, P. (2014). The maintenance of cross-domain associations in the episodic buffer. Journal of Experimental Psychology: Learning, Memory, and Cognition, 40(4), 1096-1109. DOI: https://doi.org/10.1037/a0035783 
Lemaire, B., \& Portrat, S. (2018). A Computational Model of Working Memory Integrating TimeBased Decay and Interference. Frontiers in psychology, 9(416). DOI: https://doi.org/10.3389/ fpsyg.2018.00416

Liefooghe, B., Barrouillet, P., Vandierendonck, A., \& Camos, V. (2008). Working memory costs of task switching. Journal of Experimental Psychology: Learning, Memory, and Cognition, 34(3), 478-494. DOI: https://doi.org/10.1037/0278-7393.34.3.478

Lucidi, A., Langerock, N., Hoareau, V., Lemaire, B., Camos, V., \& Barrouillet, P. (2016). Working memory still needs verbal rehearsal. Memory \& Cognition, 44(2), 197-206. DOI: https://doi.org/10.3758/s13421015-0561-Z

Morey, R. D., \& Rouder, J. N. (2015). BayesFactor (Version 0.9.10-2) [Computer Software].

Neath, I., VanWormer, L. A., Bireta, T. J., \& Surprenant, A. M. (2014). From Brown-Peterson to continual distractor via operation span: A SIMPLE account of complex span. Canadian Journal of Experimental Psychology/Revue canadienne de psychologie expérimentale, 68(3), 204-211. DOI: https://doi. org/10.1037/cep0000018

Oberauer, K., \& Lewandowsky, S. (2011). Modeling working memory: a computational implementation of the Time-Based Resource-Sharing theory. Psychonomic bulletin \& review, 18, 10-45. DOI: https://doi. org/10.3758/s13423-010-0020-6

Oberauer, K., Lewandowsky, S., Awh, E., Brown, G. D. A., Conway, A., Cowan, N., ... Ward, G. (2018). Benchmarks for models of short-term and working memory. Psychological bulletin, 144(9), 885-958. DOI: https://doi.org/10.1037/bul0000153

Oberauer, K., Lewandowsky, S., Farrell, S., Jarrold, C., \& Greaves, M. (2012). Modeling working memory: An interference model of complex span. Psychonomic bulletin \& review, 19(5), 779-819. DOI: https://doi.org/10.3758/s13423-012-0272-4

Peterson, L., \& Peterson, M. J. (1959). Short-term retention of individual verbal items. Journal of experimental psychology, 58(3), 193-198. DOI: https://doi.org/10.1037/h0049234

Portrat, S., \& Lemaire, B. (2015). Is Attentional Refreshing in Working Memory Sequential? A Computational Modeling Approach. Cognitive Computation, 7(3), 333-345. DOI: https://doi.org/10.1007/ s12559-014-9294-8

Raye, C. L., Johnson, M. K., Mitchell, K. J., Greene, E. J., \& Johnson, M. R. (2007). Refreshing: A minimal executive function. Cortex, 43(1), 135-145. DOI: https://doi.org/10.1016/S0010-9452(08)70451-9

Ricker, T. J. (2015). The role of short-term consolidation in memory persistence. AIMS Neuroscience, 2 , 259-279. DOI: https://doi.org/10.3934/Neuroscience.2015.4.259

Ricker, T. J., \& Cowan, N. (2010). Loss of visual working memory within seconds: The combined use of refreshable and non-refreshable features. Journal of Experimental Psychology: Learning, Memory, and Cognition, 36(6), 1355-1368. DOI: https://doi.org/10.1037/a0020356

Ricker, T. J., \& Cowan, N. (2014). Differences between presentation methods in working memory procedures: A matter of working memory consolidation. Journal of Experimental Psychology: Learning, Memory, and Cognition, 4O(2), 417-428. DOI: https://doi.org/10.1037/a0034301

Rouder, J. N., Morey, R. D., Speckman, P. L., \& Province, J. M. (2012). Default Bayes factors for ANOVA designs. Journal of Mathematical Psychology, 56(5), 356-374. DOI: https://doi.org/10.1016/j.jmp.2012.08.001

Vergauwe, E., Barrouillet, P., \& Camos, V. (2009). Visual and spatial working memory are not that dissociated after all: A time-based resource-sharing account. Journal of Experimental Psychology: Learning, Memory, and Cognition, 35(4), 1012-1028. DOI: https://doi.org/10.1037/a0015859

Vergauwe, E., Barrouillet, P., \& Camos, V. (2010). Do mental processes share a domain-general resource? Psychological science, 21(3), 384-390. DOI: https://doi.org/10.1177/0956797610361340

Vergauwe, E., Camos, V., \& Barrouillet, P. (2014). The impact of storage on processing: How is information maintained in working memory? Journal of Experimental Psychology: Learning, Memory, and Cognition, 4O(4), 1072-1095. DOI: https://doi.org/10.1037/a0035779

Vergauwe, E., \& Cowan, N. (2014). A common short-term memory retrieval rate may describe many cognitive procedures. Frontiers in Human Neuroscience, 8. DOI: https://doi.org/10.3389/fnhum.2014.00126

Vergauwe, E., Dewaele, N., Langerock, N., \& Barrouillet, P. (2012). Evidence for a central pool of general resources in working memory. Journal of Cognitive Psychology, 24(3), 359-366. DOI: https://doi.org/10 .1080/20445911.2011.640625

Vergauwe, E., Hartstra, E., Barrouillet, P., \& Brass, M. (2015). Domain-general involvement of the posterior frontolateral cortex in time-based resource-sharing in working memory: An fMRI study. Neuroimage, 115, 104-116. DOI: https://doi.org/10.1016/j.neuroimage.2015.04.059 
How to cite this article: Ricker, T. J., \& Vergauwe, E. 2020 Consistent Failure to Produce a Cognitive Load Effect in Visual Working Memory Using a Standard Dual-Task Procedure. Journal of Cognition, 3(1): 15, pp. 1-10. DOI: https://doi.org/10.5334/joc.108

Submitted: 17 April 2020

Accepted: 23 June 2020

Published: 10 July 2020

Copyright: (c) 2020 The Author(s). This is an open-access article distributed under the terms of the Creative Commons Attribution 4.0 International License (CC-BY 4.0), which permits unrestricted use, distribution, and reproduction in any medium, provided the original author and source are credited. See http://creativecommons.org/ licenses/by/4.0/.

] $\mathbf{u}$ J Journal of Cognition is a peer-reviewed open access journal published by Ubiquity

OPEN ACCESS $\odot$ 